\title{
Cholesterol Lowering in Low Density Lipoprotein Receptor Knockout Mice Overexpressing Apolipoprotein E
}

\author{
Jun-ichi Osuga, ${ }^{*}$ Mari Yonemoto, ${ }^{\ddagger}$ Nobuhiro Yamada, ${ }^{\star}$ Hitoshi Shimano, ${ }^{*}$ Hiroaki Yagyu, ${ }^{\star}$ Ken Ohashi, ${ }^{*}$ Kenji Harada, \\ Toshio Kamei, ${ }^{\ddagger}$ Yoshio Yazaki, ${ }^{*}$ and Shun Ishibashi* \\ *The Third Department of Internal Medicine, Faculty of Medicine, University of Tokyo, 7-3-1 Hongo, Bunkyo-ku, Tokyo 113-8655, \\ Japan; and ${ }^{\ddagger}$ Tsukuba Research Institute, Banyu Pharmaceutical Co., Ltd., 3 Okubo, Tsukuba, Ibaragi 300-33, Japan
}

\begin{abstract}
Apo $\mathrm{E}$ is a key molecule in the lipoprotein metabolism; thus, genetic manipulation of apo $\mathrm{E}$ may prove useful in the treatment of hypercholesterolemia. To test the feasibility of this idea, we have generated low density lipoprotein receptor (LDLR) knockout mice that overexpress the rat apo $E$ transgene $\left(E T g^{+/+}: L D L R K O\right)$, and compared their plasma lipoprotein profiles with those of nonexpressing LDLR knockout mice $\left(E \mathrm{Tg}^{-/-}: L D L R K O\right)$. On a normal chow diet, the mean plasma cholesterol level of $\mathrm{ETg}^{+/+}: L D L R K O$ mice was significantly lower than that of $E T^{-/-}: L D L R K O$ mice (189 versus $240 \mathrm{mg} / \mathrm{dl}, P<0.01$ ). The LDL fraction was selectively reduced in the $E T g^{+/+}: L D L R K O$ mice. Despite the challenge with an atherogenic diet, cholesterol lowering was persistently observed and fatty streak lesions in the aortic sinus were significantly suppressed in the mice overexpressing apo E. These results imply that stimulation of hepatic production of apo $\mathrm{E}$ may be used as a promising adjunctive therapy for homozygous familial hypercholesterolemia. $(J$. Clin. Invest. 1998. 102:386-394.) Key words: apo E • low density lipoprotein receptor $\bullet$ hypercholesterolemia $\bullet$ knockout mouse $\bullet$ atherosclerosis
\end{abstract}

\section{Introduction}

Apo E plays a crucial role in the metabolism of plasma lipoproteins (1). Apo $\mathrm{E}$ is produced primarily by the liver and distributed in all classes of lipoproteins. In particular, the plasma metabolism of triglyceride (TG) $)^{1}$-rich lipoproteins such as chy-

J. Osuga and M. Yonemoto contributed equally to this work.

Address correspondence to Shun Ishibashi, The Third Department of Internal Medicine, Faculty of Medicine, University of Tokyo, 7-3-1 Hongo, Bunkyo-ku, Tokyo 113-8655, Japan. Phone: 81-3-38155411 (Ext. 3129); FAX: 81-3-5802-2955; E-mail: ishibash-tky@umin. u-tokyo. ac.jp

Received for publication 7 July 1997 and accepted in revised form 21 May 1998.

1. Abbreviations used in this paper: $\mathrm{CR}$, chylomicron remnants; FCR, fractional catabolic rate; HPLC, high performance liquid chromatography; IDL, intermediate density lipoprotein; LDLR, low density lipoprotein receptor; SRID, single radial immunodiffusion; TC, total cholesterol; TG, triglyceride.

J. Clin. Invest.

(C) The American Society for Clinical Investigation, Inc. 0021-9738/98/07/0386/09 \$2.00

Volume 102, Number 2, July 1998, 386-394

http://www.jci.org lomicron, VLDL, and intermediate density lipoprotein (IDL) is profoundly influenced by apo E. Several distinct mechanisms have been proposed to explain the role of apo $E$ in the metabolism of TG-rich lipoproteins. First, apo E binds to the low density lipoprotein receptor (LDLR) with a high affinity, thereby facilitating the LDLR-mediated hepatic lipoprotein uptake $(2,3)$. Second, apo E binds to cell surface proteoglycans, thereby sequestering the apo E-containing lipoproteins to the surface of cells such as hepatocytes and vascular endothelial cells in the space of Disse of the liver (4). Third, evidence suggests that other endocytic lipoprotein receptors are involved in the hepatic uptake of chylomicron remnants (CR), lipoproteins extremely rich in apo $\mathrm{E}(5,6)$. Herz and his colleagues have shown that LDLR-related protein, a multifunctional behemoth receptor belonging to the LDLR gene family, is responsible for the hepatic uptake of CR in the absence of the LDLR (7-9).

Therapeutic application of this property of apo E has been vigorously sought. We and Mahley et al. demonstrated a transient acute reduction in plasma cholesterol levels by 20-40\% after intravenous administration of purified apo E (6-70 mg) into Watanabe heritable hyperlipidemic rabbits, an animal lacking normal $\operatorname{LDLR}(10,11)$. Repeated injection of apo E $(10 \mathrm{mg})$ three times a week, however, did not affect the plasma cholesterol levels, even though the progression of atherosclerosis was suppressed by $50 \%$ (12).

To know whether sustained supply of exogenous apo E has a cholesterol-lowering effect, we developed a line of transgenic mice that overexpress rat apo E under control of metallothionein promoter $(E T g)$ (13). The plasma levels of total cholesterol (TC) and TG were reduced in these mice particularly after treatment with zinc, which induces the expression of the transgene, even after feeding with a high-fat, high-cholesterol diet. The cholesterol lowering may result from augmented hepatic uptake of the lipoproteins, because ${ }^{125}$ I-labeled VLDL or LDL were cleared from the plasma faster in these ETg mice (14). In addition, the plasma excursions of retinyl ester, an indicator of chylomicron and $\mathrm{CR}$, were markedly suppressed in the ETg mice, after intragastric bolus administration of retinol (14). Based on these results, we proposed that the overexpressed apo E enhances the plasma clearance of lipoproteins of both hepatic and intestinal origin. However, whether or not the pathway by which this clearance is mediated involves the LDLR remains unknown.

The present study was undertaken to test the feasibility of the idea that genetic manipulation of apo $E$ is useful for the treatment of hypercholesterolemia arising from the LDLR deficiency. We have cross-bred the ETg mice to LDLR knockout ( $L D L R K O)$ mice, generated $L D L R K O$ mice possessing the apo $\mathrm{E}$ transgene in a heterozygous $\left(E T g^{+/-}: L D L R K O\right)$ or homozygous form $\left(E \mathrm{Tg}^{+/+}: L D L R K O\right)$, and compared their plasma lipoprotein metabolism and atherosclerosis with those of nonexpressing $L D L R K O\left(E T g^{-/-}: L D L R K O\right)$ mice. 


\section{Methods}

Mice. Generation of ETg (13) and LDLRKO mice (15) were described in the indicated references. PCR was performed to determine the wild-type and mutated LDLR allele using the following sets of primers: primer A ( $5^{\prime}$-GATGCCAGGATGGCAA- $\left.3^{\prime}\right)$ and primer B (5'-CGCAGTGCTCCTCATCTGAC-3'), yielding a 354-bp fragment for the wild-type allele and a $1.7-\mathrm{kb}$ fragment for the disrupted allele; and primer C (5'-GATTGGGAAGACAATAGCAGGCATGC-3') and primer D (5'-GGCAAGATGGCTCAGCAAGCAAGCAAAGGC-3'), yielding a 1.49 -kb fragment for the disrupted allele. Southern blot analyses for the apo E transgene was described previously (13). The radioactivities were measured by BAS2000 (Fuji Film, Tokyo, Japan) to discriminate between the heterozygotes and homozygotes. Male $L D L R K O$ mice were mated to female $E T g$ mice. The resulting offspring, which were heterozygous for the apo $E$ transgene and were obligatorily heterozygous for the disrupted LDLR locus $\left(E T g^{+/-}: L D L R^{+-}\right)$, were further bred to $L D L$ $R K O$ mice to produce $L D L R K O$ mice heterozygous for the apo $\mathrm{E}$ transgene $\left(E T g^{+-}: L D L R^{-1-}=E T g^{+/-}: L D L R K O\right)$. Brother-sister mating of the $E T g^{+/-}: L D L R K O$ mice was performed to generate $E T g^{-1-}: L D L R K O, E T g^{+-}: L D L R K O$, and $E T g^{+/+}: L D L R K O$ mice with comparable genetic background: $50 \%$ from C57BL/6J, $37.5 \%$ from $129 \mathrm{~Sv}$, and $12.5 \%$ from DBA $/ 2$.

Mice were maintained on a 12-h dark/light cycle and were allowed access to food and water ad libitum. Two diets were used: $(a)$ a normal chow diet (Lab Diet 5002, PMI Feeds, Inc., St. Louis, MO) that contained $4.5 \%$ animal fat and $0.025 \%$ cholesterol, $1.16 \mathrm{mM} \mathrm{Zn}$, $1.36 \mathrm{mM} \mathrm{Mn}, 0.27 \mathrm{mM} \mathrm{Cu}, 0.01 \mathrm{mM} \mathrm{Fe}$, and $0.04 \mathrm{mM} \mathrm{Cr} ;(b)$ a $1.25 \%$ cholesterol/atherogenic diet (three parts of the normal diet mixed with one part of a cholesterol, cocoa butter, casein, and sodium cholate diet [Thomas Hartroft diet; PMI Foods Inc.]). The final diet contained $1.25 \%$ cholesterol, $7.5 \%$ cocoa butter, $7.5 \%$ casein, and $0.5 \%$ sodium cholate (16). For induction of the metallothionein promoter, water supplemented with $20 \mathrm{mM} \mathrm{ZnSO}_{4}$ was administered for $>2$ wk (13). Experiments were performed in accordance with institutional guidelines. Unless otherwise stated, mice aged between 12-16 wk were used for the experiments.

Plasma lipid analysis. Blood was collected from the retroorbital plexus into a tube containing EDTA after a 12-h fast, and plasma was separated by centrifugation and mixed with $1 / 500 \mathrm{vol}$ of a solution containing $60 \mathrm{mg} / \mathrm{ml}$ of benzamidine. TC and TG concentrations were determined enzymatically using kits (Determiner TC555 and Determiner TG555; Kyowa Medex, Tokyo, Japan). For lipoprotein analyses, the plasma was immediately applied to high performance liquid chromatography (HPLC) or sequential ultracentrifugation. HPLC analyses were performed according to a modified method of Hara and Okazaki (16). $5 \mu$ l of plasma was applied to a combined column system composed of two TSK gel Lipopropacks (TOSOH; Tokyo, Japan) in tandem, and eluted with the supplied buffer (TSK eluent LP1; $\mathrm{TOSOH}$ ) at a rate of $0.5 \mathrm{ml} / \mathrm{min}$. TC concentrations in the effluents were monitored using a kit (Determiner TC555). Areas under the elution curves for HDL and non-HDL peaks were determined. These values and plasma TC levels were used to calculate non-HDL- and HDL-cholesterol concentrations.

Quantitation of apo B. Plasma apo B concentrations were determined by isopropanol precipitation method as described (17). In brief, $100 \mu \mathrm{l}$ of plasma was obtained from an individual mouse and ultracentrifuged at a density of $1.063 \mathrm{~g} / \mathrm{ml}$. An aliquot of the top $d<$ $1.063 \mathrm{~g} / \mathrm{ml}$ lipoprotein fraction was mixed with an equal volume of isopropanol in a microfuge tube, incubated at room temperature for $1 \mathrm{~h}$, and centrifuged at $10,000 \mathrm{~g}$ for $15 \mathrm{~min}$. The resulting protein pellets were solubilized in $0.1 \mathrm{~N} \mathrm{NaOH}$, and protein concentrations were determined by a kit (BCA protein assay reagent; Pierce, Rockford, IL). In parallel, apo B concentrations were determined by a single radial immunodiffusion (SRID) technique using a kit designed for measurement of human apo B levels (Apo B plate 'Daiichi'; Daiichi Pure Chemicals, Tokyo, Japan), according to a manufacturer's instruction
(18). When the same amounts of LDL apo B were applied to the plates, mouse LDL apo B produced a 8.7 -fold larger precipitation ring in diameter than human LDL apo B. The results of the isopropanol precipitation method were correlated with those of the SRID method with $r^{2}>0.99 ; n=9$.

Quantitation of apo E. Immunoblot analyses were performed to determine plasma apo E levels. $1 \mu \mathrm{l}$ of plasma was subjected to both SDS $/ 3-15 \%$ PAGE and isoelectric focusing (IEF) (Phenotyping apo E IEF system; Joko, Tokyo, Japan) (19). After proteins were electrophoretically transferred to nitrocellulose filters (Hybond ECL ${ }^{\circledR}$; Amersham Corp., Arlington Heights, IL) in a buffer containing $20 \mathrm{mM}$ Tris, $150 \mathrm{mM}$ glycine, $0.02 \%$ SDS, and $20 \%$ methanol at $200 \mathrm{~mA}$ for $6 \mathrm{~h}$, immunoblotting was performed using a rabbit anti-rat apo E polyclonal antibody as the first antibody and ${ }^{125} \mathrm{I}$-protein A $(2,000 \mathrm{cpm} / \mathrm{ng}$, $0.5 \mu \mathrm{g} / \mathrm{ml}$; Amersham Corp.) as described (13). The radioactive images of the filters were analyzed by BAS2000. Apo E was purified from either rat or mouse plasma, as previously described (10), and used for calibration.

The following four variables were measured: $\mathrm{X}$, relative radioactivity of the sample apo E compared to the standard rat apo E on SDS-PAGE; Y, proportion of the radioactivities in rat apo $\mathrm{E}$ (three bands together) in all the apo $\mathrm{E}$ radioactivities (rat plus mouse) on IEF; A, radioactivity of the standard rat apo E; and B, the antibody's immunoreactivity for rat apo E compared to that for mouse apo E. Rat and mouse apo E concentrations were calculated from the following formulas: Rat apo $\mathrm{E}$ concentration $=\mathrm{X} \times \mathrm{Y} / \mathrm{A}$; Mouse apo $\mathrm{E}$ concentration $=\mathrm{B} \times \mathrm{X} \times(1-\mathrm{Y}) / \mathrm{A}$.

Analyses of plasma lipoprotein and apolipoproteins. Preparative ultracentrifugation was performed to obtain CM+VLDL $(d<1.006$ $\mathrm{g} / \mathrm{ml})$, IDL $(d 1.006-1.019 \mathrm{~g} / \mathrm{ml})$, LDL $(d 1.019-1.063 \mathrm{~g} / \mathrm{ml})$ and HDL (d $1.063-1.21 \mathrm{~g} / \mathrm{ml})$ from the pooled plasma as described (20). TC contents were measured and represented as $\mathrm{mg} / \mathrm{dl}$ of original plasma.

After dialysis against saline containing $0.2 \mathrm{mM}$ EDTA and $1 \mathrm{mM}$ PMSF, each lipoprotein fraction was delipidated overnight at $-20^{\circ} \mathrm{C}$ with $20 \mathrm{vol}$ of ice-cold ethanol-diethyl ether $(3: 1, \mathrm{vol} / \mathrm{vol})$, and the apolipoproteins were pelleted by centrifugation for $20 \mathrm{~min}$ at $-10^{\circ} \mathrm{C}$, $1,000 \mathrm{~g}(21)$. The pellets were extracted twice with cold anhydrous diethyl ether, and subjected to SDS $/ 3-15 \%$ PAGE. Proteins were visualized by staining with Commassie brilliant blue. The intensities of the bands were determined by densitometric scanning and quantitated by National Institutes of Health Image software (Bethesda, MD).

Plasma lipoprotein kinetics. After a 12-h fast, blood was obtained from $E T g^{-/-}: L D L R K O$ or $E T g^{+/+}: L D L R K O$ mice $(n=10)$ that had been maintained on water supplemented with zinc and a normal chow, and pooled for lipoprotein isolation. VLDL $(d<1.006 \mathrm{~g} / \mathrm{ml})$ and LDL $(d 1.019-1.063 \mathrm{~g} / \mathrm{ml})$ were isolated by ultracentrifugation and refloated at the same density to increase the purity. VLDL obtained from $E T g^{-1-}: L D L R K O$ or $E T g^{+/+}: L D L R K O$ mice are denoted as E-VLDL or E+VLDL, respectively. These lipoproteins and the infranatant $d>1.063 \mathrm{~g} / \mathrm{ml}$ fraction were dialyzed against saline containing $1 \mathrm{mM}$ sodium phosphate, $\mathrm{pH}$ 7.4, 0.2 mM EDTA, and $1 \mathrm{mM}$ PMSF. The lipoproteins were labeled with ${ }^{125} \mathrm{I}$ by iodine monochloride method (22), and dialyzed as described above. After removing EDTA and PMSF by dialysis against PBS, the labeled lipoproteins were mixed with the $d>1.063 \mathrm{~g} / \mathrm{ml}$ fraction, and diluted with PBS containing $10 \mathrm{mg} / \mathrm{ml} \mathrm{BSA}$ to $40 \mu \mathrm{g} / \mathrm{ml} .100 \mu \mathrm{l}$ (equivalent to $4 \mu \mathrm{g}$ protein of the lipoprotein) was injected as a bolus into the jugular vein of mice that had been maintained on water containing zinc for $2 \mathrm{wk}$, under anesthesia with pentobarbital. Subsequently, blood was collected from the retroorbital plexus at the indicated times. Apo B-associated radioactivities were determined by the isopropanol precipitation method as described (14). The value at $1 \mathrm{~min}$ after injection was used as $100 \%$. Fractional catabolic rate (FCR) and production rate were calculated according to Matthews (23).

Vitamin A fat tolerance test. After a 4-h fast, $100 \mu \mathrm{l}$ of Chocola $\mathrm{A}^{\circledR}$ (Eisai Co., Ltd.; Tokyo, Japan) containing $2 \mathrm{mg}$ of retinyl palmitate and $10.6 \mathrm{mg}$ castor oil was administered as a bolus through a gastric cannula to mice that had been maintained on water supple- 
mented with zinc, without anesthesia. Blood was collected from the retroorbital plexus at the indicated times. Plasma was immediately separated and stored wrapped in foil at $-20^{\circ} \mathrm{C}$. After extraction with hexane from pooled plasma, the lipids were subjected to HPLC for the measurement of retinyl palmitate and retinol, as previously described (14).

Pathology. The hearts and attached aortas were removed, fixed with saline containing $4 \%$ formalin, embedded in $25 \%$ gelatin, and sectioned as described (24). Briefly, $10 \mu \mathrm{m}$ cross-sections were taken sequentially, starting just above the aortic valve and moving along the ascending aorta. Five sections, each separated by $120 \mu \mathrm{m}$, were used to evaluate the lesions. Fatty streak lesions were stained using Oil Red O. The lesion area of each section was estimated by a digitizing tablet (NEC PC-8875 personal TABLET).

Statistics. Student's $t$ test was used to compare the values between two groups.

\section{Results}

Expression of rat apo E. Immunoblot analyses were performed to measure the plasma concentration of apo $\mathrm{E}$ (Fig. 1). Fig. $1 A$ compares the intensities of bands corresponding to apo E purified from mice and rats, when the same amounts (75 ng) were loaded to the gels; the antibody had twofold higher immunoreactivity for rat apo $\mathrm{E}$ than for mouse apo E. Fig. $1 B$ shows immunoblots of SDS-PAGE (top) and IEF (bottom) for the plasma apo $\mathrm{E}$ of the three types of mice before and after zinc treatment. SDS-PAGE revealed that plasma apo E levels were higher in the mice having the rat apo E transgene than those without it in the following order before zinc treatment: $E T g^{+/+}: L D L R K O>E T g^{+/-}: L D L R K O>E T g^{-1-}: L D L R K O$. After zinc treatment, plasma apo $E$ levels were further increased in the $E T g^{+/-}: L D L R K O$ mice. Upon IEF, mouse apo $\mathrm{E}$ was focused as a single band, and rat apo $\mathrm{E}$ was focused as three bands that were more acidic than mouse apo E. Presumably, the most basic band of rat apo $\mathrm{E}$ is nonsialidated apo $\mathrm{E}$ and the second and third bands are with one and two molecules of sialic acid, respectively. Furthermore, the IEF results confirm that rat apo $\mathrm{E}$ was present only in the $E T g^{+/-}: L D L$ $R K O$ and $E T g^{+/+}: L D L R K O$ mice, but not in the $E T g^{-1-}$ : LDLRKO.

Table I summarizes the calculated values for the plasma levels of rat and mouse apo E. Before zinc treatment, the $E T g^{+/-}: L D L R K O$ and $E T g^{+/+}: L D L R K O$ mice had rat apo E in the plasma in amounts comparable to $50 \%$ of mouse endogenous apo E. The $E \operatorname{Tg}^{+/+}: L D L R K O$ mice had $40 \%$ higher concentrations of rat apo $\mathrm{E}$ than the $E \mathrm{Tg}^{+/-}: L D L R K O$ mice. After zinc treatment, the rat apo E levels were increased by $38 \%$ in the $E T g^{+/-}: L D L R K O$ mice and by $23 \%$ in the $E T g^{+/+}$:
A

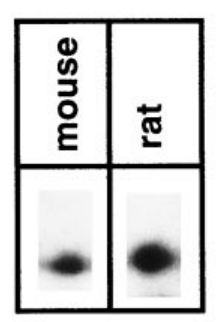

B

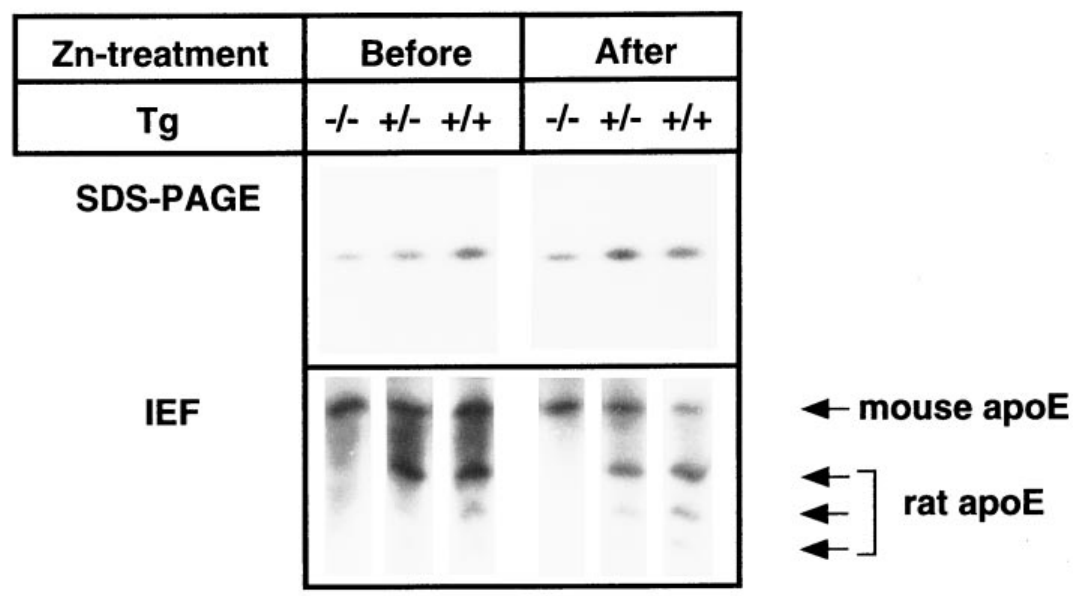

C

\begin{tabular}{|c|c|c|c|c|}
\hline Lipoproteins & VLDL & IDL & LDL & HDL \\
\hline $\mathrm{Tg}$ & $+1++1--1-$ & $+1++1--1-$ & $1+1++1--1-$ & $+1++1--1-$ \\
\hline
\end{tabular}

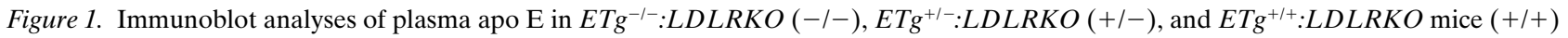
maintained on a normal chow. $(A)$ Difference of the immunoreactivity of the antibody. The same amount of rat and mouse apo $\mathrm{E}(75 \mathrm{ng})$ was subjected to SDS-PAGE. (B) Immunoblots of apo E separated by SDS-PAGE and IEF. Blood was collected from four mice with the indicated genotypes after a 12-h fast, before and after treatment with zinc. $1 \mu$ lof pooled plasma was subjected to SDS-PAGE and IEF analyses. $(C)$ Immunoblots of apo E in VLDL, IDL, LDL, and HDL. Lipoproteins were separated from pooled plasma $(n=10)$ after treatment with zinc by sequential ultracentrifugation. Each lipoprotein fraction equivalent to $2 \mu 1$ of original plasma was subjected to SDS-PAGE. 
Table I. Plasma Apo E Levels

\begin{tabular}{|c|c|c|c|c|c|}
\hline $\mathrm{Tg}$ & $n$ & $\mathrm{Zn}$ & Total apoE & Mouse apoE & Rat apoE \\
\hline & & & & $m g / d l$ & \\
\hline \multirow[t]{2}{*}{$-1-$} & 4 & Before & $19.7 \pm 3.7$ & $19.7 \pm 3.7$ & 0 \\
\hline & & After & $18.4 \pm 1.8$ & $18.4 \pm 1.8$ & 0 \\
\hline \multirow[t]{2}{*}{$+1-$} & 4 & Before & $22.8 \pm 2.7$ & $15.5 \pm 0.7$ & $7.2 \pm 2.9$ \\
\hline & & After & $26.5 \pm 1.2^{\ddagger}$ & $16.6 \pm 1.4^{\S}$ & $9.9 \pm 2.5^{\|}$ \\
\hline \multirow[t]{2}{*}{$+1+$} & 4 & Before & $27.4 \pm 3.5^{*}$ & $17.1 \pm 1.9$ & $10.3 \pm 2.0$ \\
\hline & & After & $26.2 \pm 2.3^{\ddagger}$ & $13.6 \pm 1.1^{\dagger} \|$ & $12.7 \pm 3.2$ \\
\hline
\end{tabular}

$E T g^{-/-}: L D L R K O(-/-), E T g^{+/-}: L D L R K O(+/-)$, and $E T g^{+/+}: L D L-$ $R K O$ mice $(+/+)$ were maintained on a normal chow diet. Blood was collected before and after treatment with zinc for 2 wk. Plasma apo E levels were determined by immunoblot analyses as described in Methods. The values are expressed as means \pm SD. $* P<0.05$ versus before of $-/-;{ }^{\ddagger} P<0.001$ versus after of $-/-;{ }^{\S} P<0.01$ versus after of $+/-$ and $-/-; \| P<0.05$ after versus before.

$L D L R K O$ mice. But the mouse apo E levels were decreased in the $\mathrm{ETg}^{+/+}: L D L R K O$ mice; therefore, the combined apo E concentrations were not changed.

Fig. $1 C$ illustrates the combined apo E levels in each lipoprotein fraction from the three types of mice treated with zinc. In any lipoprotein classes, the $L D L R K O$ mice with rat apo $\mathrm{E}$ transgene had more apo $\mathrm{E}$ than the $L D L R K O$ mice without the transgene. The apo E contents were highest in LDL fraction irrespective of the presence of the transgene. Mild genedosage effects were seen in VLDL and IDL fraction.

Plasma lipoprotein profiles. To determine whether constitutive expression of the apo $\mathrm{E}$ transgene alters plasma lipid levels, the plasma TC and TG levels were compared between the three types of mice, before and after zinc treatment (Table II). Before zinc treatment, neither plasma TC nor TG differed significantly between these mice. After zinc treatment for $2 \mathrm{wk}$, the plasma TC levels decreased by $20 \%$ in the $E T g^{+/}: L D L-$
Table II. Plasma Lipid Levels

\begin{tabular}{|c|c|c|c|c|c|c|}
\hline $\mathrm{Tg}$ & $n$ & $\mathrm{Zn}$ & TC & Non-HDL-C & HDL-C & TG \\
\hline & $m / f$ & & & $m g / d l$ & & \\
\hline \multirow[t]{2}{*}{$-1-$} & 15 & Before & $260 \pm 68.6$ & $137 \pm 52.6$ & $121 \pm 28.1$ & $127 \pm 55.5$ \\
\hline & $(8 / 7)$ & After & $240 \pm 60.8 *$ & $122 \pm 44.1$ & $117 \pm 28.3$ & $104 \pm 39.0$ \\
\hline \multirow[t]{2}{*}{$+1-$} & 29 & Before & $254 \pm 54.9$ & $132 \pm 38.1$ & $122 \pm 28.6$ & $124 \pm 36.0$ \\
\hline & $(12 / 17)$ & After & $203 \pm 50.0^{\S}$ & $105 \pm 32.5^{\S}$ & $108 \pm 27.9^{\ddagger}$ & $128 \pm 40.2$ \\
\hline \multirow[t]{2}{*}{$+/+$} & 16 & Before & $251 \pm 46.5$ & $128 \pm 33.8$ & $122 \pm 34.7$ & $133 \pm 42.8$ \\
\hline & $(7 / 9)$ & After & $189 \pm 31.2^{\S \|}$ & $87 \pm 17.4^{\S \|}$ & $101 \pm 31.1$ & $132 \pm 43.8$ \\
\hline
\end{tabular}

$E T g^{-/-}: L D L R K O(-/-), E_{T g^{+/-}}: L D L R K O(+/-)$, and $E T g^{+/+}: L D L-$ $R K O$ mice $(+/+)$ were maintained on a normal chow diet. Blood was collected before and after treatment with zinc for $2 \mathrm{wk}$. Plasma TC and TG levels were determined. HPLC analyses were performed for each sample. Non-HDL-cholesterol (non-HDL-C) and HDL-C were calculated from the TC levels and the HPLC profiles. The values are expressed as means \pm SD. ${ }^{*} P<0.05,{ }^{\ddagger} P<0.01,{ }^{8} P<0.0001$ after versus before. $\| P<0.01$ versus after of $-/-$.

$R K O$ and by $25 \%$ in the $E T g^{+/+}: L D L R K O$ mice, but not in the $E T g^{-1-}: L D L R K O$ mice. Such cholesterol lowering was largely attributable to the reduction in the non-HDL-C as shown in Fig. 2; the non-HDL-C was reduced by $20 \%$ in the $E g^{+/-}: L D L R K O$ mice, and by $32 \%$ in the $E T g^{+/+}: L D L R K O$ mice (Table II).

To further determine which lipoprotein fraction was affected by the expression of rat apo E, we measured the TC and apo B contents in the lipoproteins isolated from the three types of mice treated with zinc (Table III). The most outstanding changes were observed in the TC and apo B-100 contents in the LDL fraction. TC contents in the LDL were reduced by $25 \%$ in the $E T^{+/-}: L D L R K O$ mice and by $39 \%$ in the $E T^{+/+}$: $L D L R K O$ mice; apo B-100 contents in the LDL were reduced by $23 \%$ in the $E T g^{+-}: L D L R K O$ mice, and by $43 \%$ in the $E T g^{+/+}: L D L R K O$ mice. Thus, the changes in the LDL-TC appeared comparable to those in the LDL-apo B-100, indicating
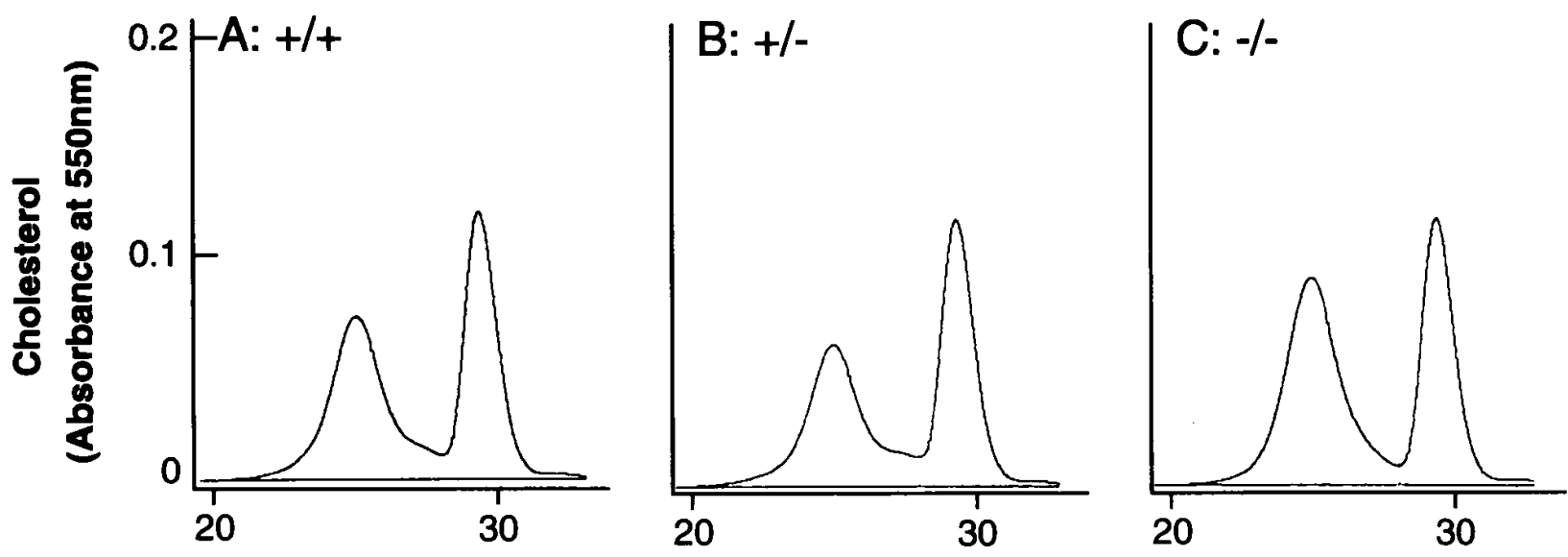

Elution Volume (ml)

Figure 2. HPLC profiles of plasma lipoproteins from mice maintained on a normal chow. Plasma was obtained from five male $E T g^{-1-}: L D L R K O$ $(A,-/-), E T g^{+/-}: \operatorname{LDLRKO}(B,+/-)$, and $E T g^{+/+}: L D L R K O$ mice $(C,+/+)$ maintained on a normal chow and water supplemented with zinc. Pooled plasma from each group was subjected to HPLC lipoprotein analysis, and cholesterol contents in effluents were monitored. 
Table III. Cholesterol, Apo B-100, and Apo B-48 Composition in the Plasma Lipoproteins

\begin{tabular}{lccccc}
\hline & Tg & VLDL & IDL & LDL & HDL \\
\hline \multirow{4}{*}{ Cholesterol } & & & $m g / d l$ & & \\
& $-/-$ & 26 & 20 & 115 & 75 \\
& $+/-$ & 35 & 12 & 86 & 82 \\
Apo B-100/Apo B-48 & $+/+$ & 25 & 11 & 70 & 80 \\
& $+/-$ & $0.8 / 1.0$ & $0.2 / 0.5$ & $89.5 / 7.0$ & N.D. \\
& $+/-$ & $0.8 / 1.2$ & $0.2 / 0.7$ & $69.2 / 5.3$ & N.D. \\
& $+/+$ & $1.3 / 1.4$ & $0.3 / 0.7$ & $50.6 / 3.8$ & N.D.
\end{tabular}

$E T g^{-/-}: \operatorname{LDLRKO}(-/-), \mathrm{ETg}^{+/-}: \operatorname{LDLRKO}(+/-)$, and $\mathrm{ETg}^{+/+}: \mathrm{LDL}^{-}$ $R K O$ mice $(+/+)$ were maintained on a normal chow diet. Blood was collected after treatment with zinc for $2 \mathrm{wk}$. VLDL, IDL, LDL, and HDL were isolated by sequential ultracentrifugation and cholesterol contents were determined enzymatically. Isopropanol precipitation method was used to determine the total apo B concentrations. Lipoproteins were subjected to SDS-PAGE, stained with Coomassie brilliant blue, and scanned by a densitometer. The concentrations of apo B-100 and apo B-48 were calculated from the values for total apo B and relative ratio between apo B-100 and apo B-48. N.D. = not determined.

that the overexpression of rat apo E reduced the particle number of the apo B-100-containing lipoproteins primarily in the LDL fraction.

SDS/PAGE of apolipoproteins shows that apo B-100, a predominant apo B species, in the LDL fraction was reduced in the $E T g^{+/-}: L D L R K O$ and $E T g^{+/+}: L D L R K O$ mice, compared to the $E T g^{-1-}: L D L R K O$ mice (Fig. 3). VLDL and IDL contained less apo B-100 than LDL, and there was no signifi- cant difference in its contents between the three types of mice. Consistent with the immunoblot results (Fig. 1), the $\mathrm{ETg}^{+/-}$: $L D L R K O$ and $E T g^{+/+}: L D L R K O$ mice contained more apo E than the $E T g^{-1-}: L D L R K O$ mice, especially in the VLDL fraction. No significant difference was observed in the composition of the other apolipoproteins such as apo A-I and apo B-48 between the three types of mice.

Lipoprotein kinetics studies. To clarify how the overexpression of rat apo E reduced plasma cholesterol levels even in the absence of the LDLR, lipoprotein kinetics studies were performed (Fig. 4). When injected into wild-type mice with the functional LDLR, ${ }^{125}$ I-labeled E+VLDL was cleared faster than ${ }^{125}$ I-labeled E-VLDL; their $t_{1 / 2}$ were $\sim 15$ and 25 min, respectively (Fig. $4 A$ ). The mean FCR of ${ }^{125}$ I-labeled E+VLDL were 1.6 times larger than that of ${ }^{125}$ I-labeled E-VLDL (2.17 versus 1.33 pools $/ \mathrm{h} ; P<0.05)$.

Next, ${ }^{125}$ I-labeled E+VLDL or ${ }^{125}$ I-labeled E-VLDL were injected into the $E T g^{+/+}: L D L R K O$ or $E T g^{-1-}: L D L R K O$ mice, respectively (Fig. $4 B$ ). Within the initial $3 \mathrm{~h}$, no significant difference in plasma clearance of the autologous lipoproteins was observed; $t_{1 / 2}=90 \mathrm{~min}$. After $6 \mathrm{~h}$, however, ${ }^{125}$ I-labeled $\mathrm{E}+\mathrm{VLDL}$ cleared faster than ${ }^{125} \mathrm{I}$-labeled E-VLDL. Overall, the mean FCR of ${ }^{125}$ I-labeled E+VLDL was 1.45 times larger than that of ${ }^{125} \mathrm{I}$-labeled $\mathrm{E}-\mathrm{VLDL}$ ( 0.33 versus 0.23 pools $/ \mathrm{h}$, $P<0.05)$. The mean production rate of apo $\mathrm{B}$ was calculated to be 21.2 and $18.4 \mathrm{nmol} / \mathrm{h} / \mathrm{g}$ body weight for the $E T g^{-/-}: L D L$ $R K O$ and $E T g^{+/+}: L D L R K O$ mice, respectively $(P<0.05)$.

A similar kinetic study was performed using autologous LDL. There was no difference in the plasma clearance of LDL between the $E T^{-/-}: L D L R K O$ and $E T g^{+/+}: L D L R K O$ mice up to $24 \mathrm{~h}$ (data not shown).

A vitamin A fat tolerance test did not reveal any difference in the plasma excursion of retinyl ester between the three

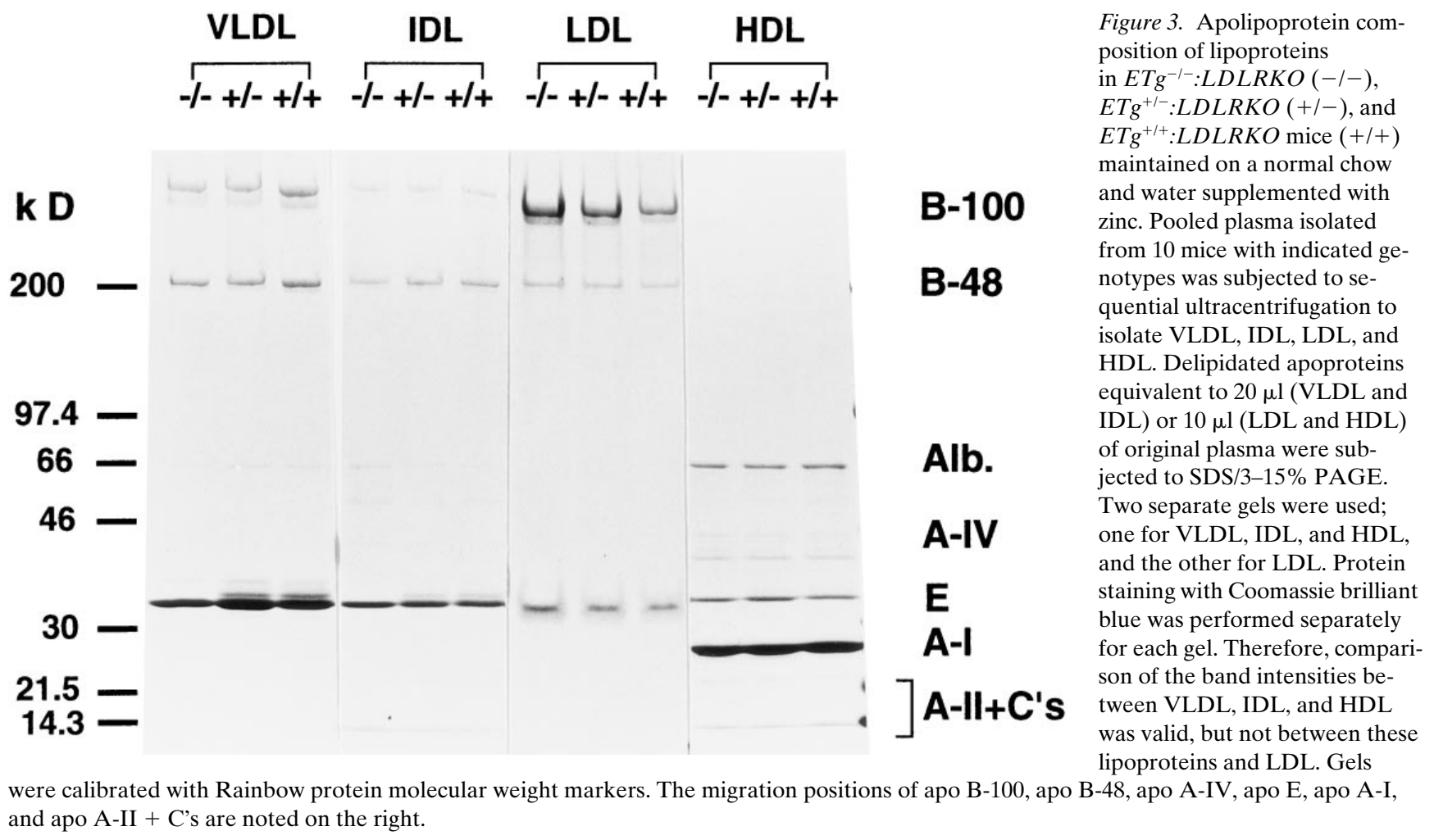



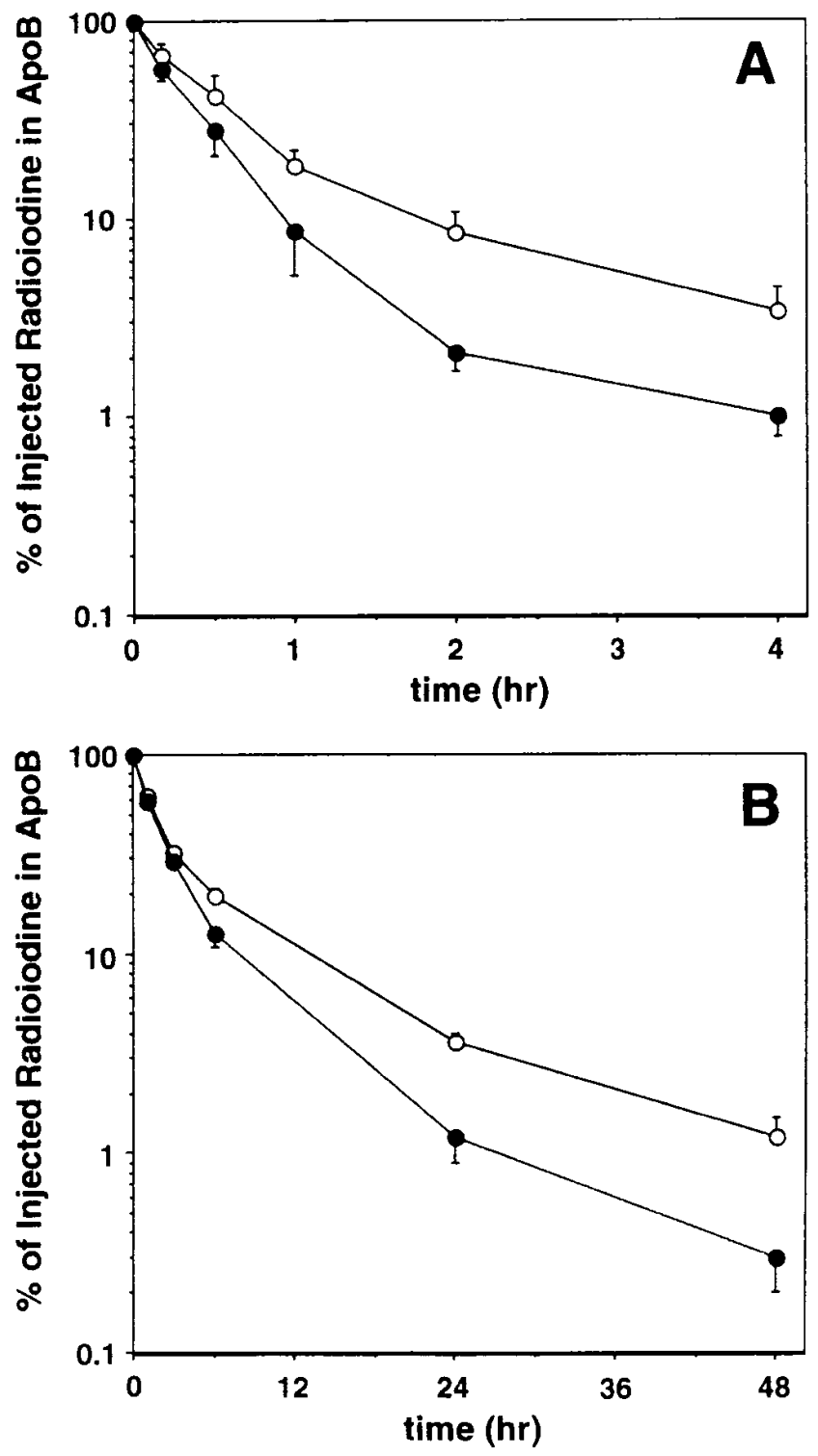

Figure 4. Plasma kinetics of ${ }^{125}$ I-labeled VLDL. VLDL were isolated from either $E T g^{-1-}: L D L R K O(\bigcirc)$ or $E T g^{+/+}: L D L R K O$ mice $(\bullet)$ that had been maintained on a normal chow and water supplemented with zinc, by ultracentrifugation at a density of $1.006 \mathrm{~g} / \mathrm{ml}$, and refloated at same density. The same lipoprotein preparations as shown in Fig. $1 C$ were used for radioiodination by iodine monochloride method. Specific activities of labeled lipoproteins were $50-200 \mathrm{cpm} /$ ng protein. $4 \mu \mathrm{g}$ protein were injected into the jugular vein of three mice, together with the autologous fraction $(d>1.063 \mathrm{~g} / \mathrm{ml})$ equivalent to the same amount of plasma from which VLDL originated. At the indicated times, blood was collected. Apo B-associated radioactivity was determined using the isopropanol precipitation method as previously described (9). The value at $1 \mathrm{~min}$ after injection was used as $100 \%$. The recipients were wild-type mice $(A)$, and autologous $E{ }^{-/-}: L D L R K O$ and $E^{-1+}: L D L R K O$ mice that had been maintained on a normal chow and water supplemented with zinc $(B)$.

types of mice (Fig. $5 A$ ). The plasma excursion curves for free retinol were also similar to each other, indicating that no difference in the absorption of vitamin A existed (Fig. $5 B$ ).

Resistance against diet-induced hypercholesterolemia. The response of plasma TC and TG levels to the feeding with a
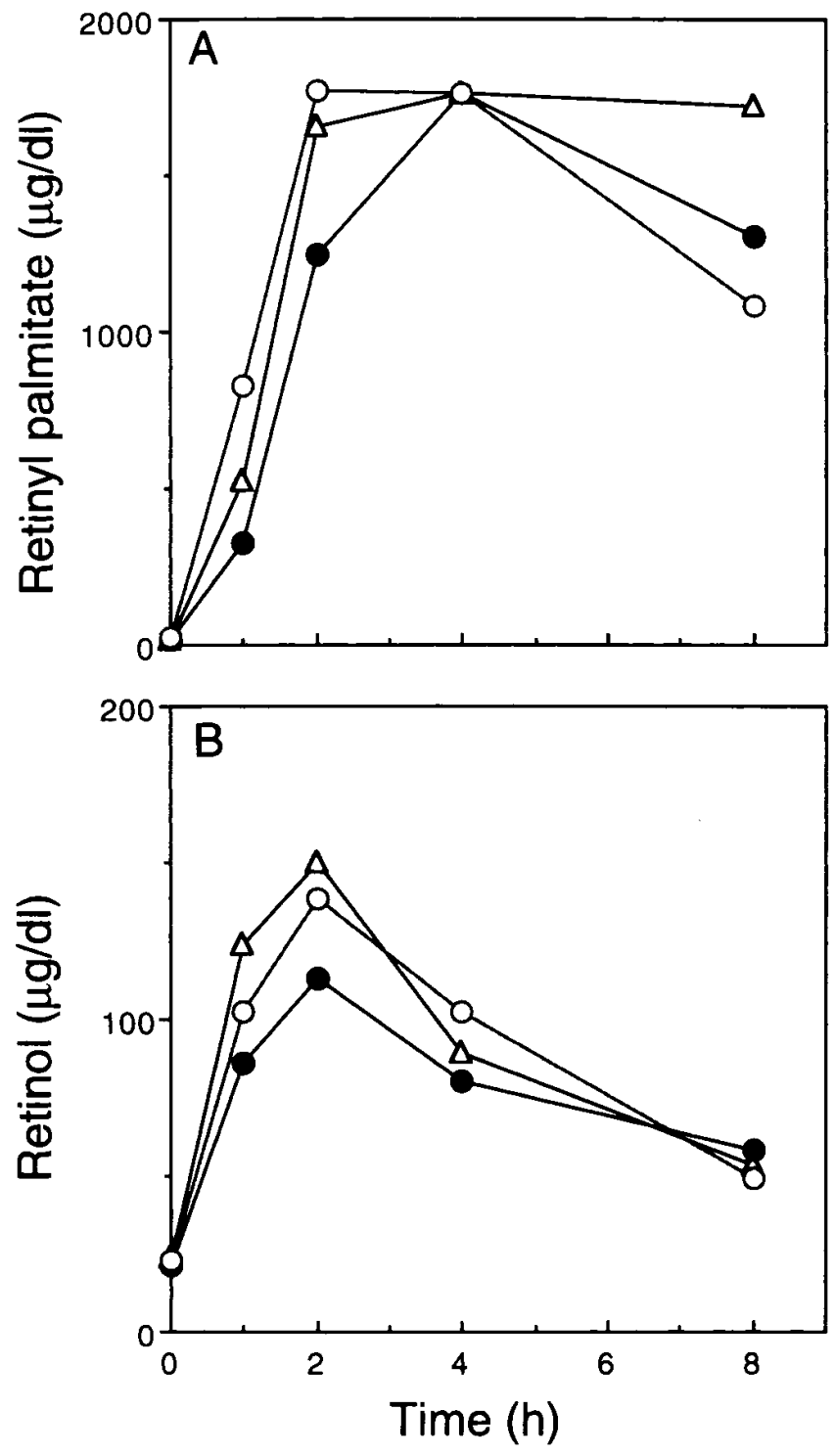

Figure 5. Vitamin A tolerance test. Aqueous retinyl palmitate $(2 \mathrm{mg}$ per animal) was administered as a bolus through a gastric cannula to the $\operatorname{ETg}^{-1-}: \operatorname{LDLRKO}(\bigcirc), \operatorname{ETg}^{+/-}: \operatorname{LDLRKO}(\bullet)$, and $\mathrm{ETg}^{+/+}$:

$L D L R K O$ mice $(\triangle)$ that had been maintained on a normal chow and water supplemented with zinc, after a 4-h fast $(n=5)$. Blood was collected at the indicated times. Plasma levels of retinyl palmitate $(A)$ and free retinol $(B)$ were determined in the pooled plasma.

$1.25 \%$ cholesterol/atherogenic diet was shown in Table IV. During the feeding, the mice had been maintained on water supplemented with zinc. The $E T g^{-1-}: L D L R K O$ mice developed severe hypercholesterolemia with a mean plasma TC level of $3,116 \mathrm{mg} / \mathrm{dl}$, which is similar to the previously reported values (16). The $E T g^{+/-}: L D L R K O$ and $E T g^{+/+}: L D L R K O$ mice exhibited milder hypercholesterolemia compared with the $E T g^{-1-}: L D L R K O$ mice, indicating that the overexpression of rat apo E suppressed diet-induced hypercholesterolemia by $23 \%$ in the $E T^{+/-}: L D L R K O$ mice and by $38 \%$ in the $E T^{+/+}$: $L D L R K O$ mice, even in the absence of the functional LDLR. Lipoprotein analyses showed that the TC contents were reduced in CM+VLDL and in IDL, but not in LDL (Table V). 
Table IV. Effects of Cholesterol Feeding on the Plasma Lipid Levels

\begin{tabular}{ccccr}
\hline $\mathrm{Tg}$ & $n$ & Zn & $\mathrm{TC}$ & \multicolumn{1}{c}{$\mathrm{TG}$} \\
\hline & $m / f$ & & $m g / d l$ & \\
$-/-$ & 15 & Before & $297 \pm 73$ & $121 \pm 33$ \\
& $(8 / 7)$ & After & $3116 \pm 1025$ & $101 \pm 59$ \\
$+/-$ & 27 & Before & $284 \pm 48$ & $111 \pm 28$ \\
& $(11 / 16)$ & After & $2394 \pm 893^{*}$ & $73 \pm 55$ \\
$+/+$ & 15 & Before & $294 \pm 47$ & $131 \pm 40$ \\
& $(6 / 9)$ & After & $1918 \pm 632^{\ddagger}$ & $66 \pm 40$
\end{tabular}

$E T g^{-/-}: \operatorname{LDLRKO}(-/-), \mathrm{ETg}^{+/-}: \operatorname{LDLRKO}(+/-)$, and $E T g^{+/+}: \mathrm{LDL}_{-}$ $R K O$ mice $(+/+)$ were initially maintained on a normal chow, and then on a $1.25 \%$ cholesterol/atherogenic diet and water supplemented with zinc for $14 \mathrm{wk}$. Blood was collected before and after the feeding. Plasma TC and TG levels were determined enzymatically. HPLC analyses were performed for each sample. Non-HDL-cholesterol (non-HDL-C) and HDL-C were calculated from the TC levels and the HPLC profiles. The values are expressed as means $\pm \mathrm{SD}$. ${ }^{*} P<0.05,{ }^{\ddagger} P<0.01$.

The concentrations of plasma apo B measured by SRID were as follows: $3,055 \pm 1,103 \mathrm{mg} / \mathrm{dl}(n=6)$ in the $E T g^{-/-}: L D L-$ $R K O, 1,505 \pm 1,093 \mathrm{mg} / \mathrm{d}(n=8)$ in the $E T g^{+/-}: L D L R K O$, and $887 \pm 715 \mathrm{mg} / \mathrm{dl}(n=11)$ in the $E T g^{+/+}: L D L R K O$ mice. $E T g^{+/+}$: $L D L R K O$ and $E T g^{+-}: L D L R K O$ mice had significantly lower plasma apo B levels than $E T g^{-1-}: L D L R K O$ mice $(P<0.05$ and $<0.001$, respectively).

Suppression of diet-induced atherosclerosis. We compared the cross-sectional lesion areas in the aortic sinus from the $E T g^{-1-}: L D L R K O$ and $E T g^{+/+}: L D L R K O$ mice after feeding with a $1.25 \%$ cholesterol/atherogenic diet (Fig. 6). The lesion areas of the $E T^{+/+}: L D L R K O$ mice were significantly smaller than those of the $E T g^{-1-}: L D L R K O$ mice by $45 \%$ $\left(124,603 \pm 41,464[n=14]\right.$ versus $68051 \pm 30525 \mu \mathrm{m}^{2}[n=16]$, $P<0.001)$.

\section{Discussion}

The present study has demonstrated that overexpression of apo $\mathrm{E}$ reduces plasma cholesterol levels even in the absence of the functional LDLR. The cholesterol lowering appears to result from the reduction of the apo B-100-containing lipoproteins in LDL. From the results of the lipoprotein kinetics studies, we speculate that both the decreased production and the increased clearance of VLDL, but not the changes in chylomicron metabolism, account for the cholesterol-lowering in the $L D L R K O$ mice overexpressing rat apo E. Furthermore, the overexpression of rat apo E suppressed diet-induced hypercholesterolemia as well as atherosclerosis.

We have previously shown that mice overexpressing apo $\mathrm{E}$ have decreased levels of plasma TC and TG, and are resistant to diet-induced hypercholesterolemia $(13,14)$. Lipoproteins kinetics studies showed the increased plasma clearance of lipoproteins such as VLDL and LDL. However, it remains unknown whether the increased clearance of the lipoproteins was mediated through the LDLR. The present study has clearly demonstrated that the overexpression of rat apo $\mathrm{E}$ has cholesterol-lowering effects even in the absence of the functional LDLR, indicating that the non-LDLR pathway is also involved in the cholesterol lowering by the apo E transgene.
Table V. Cholesterol Contents in the Lipoprotein Fraction after Cholesterol Feeding

\begin{tabular}{lcrrr}
\hline $\mathrm{Tg}$ & CM/VLDL & IDL & LDL & HDL \\
\hline & & $m g / d l$ & & \\
$-/-$ & 968 & 1010 & 336 & 8 \\
$+/-$ & 475 & 990 & 362 & 29 \\
$+/+$ & 284 & 694 & 331 & 48
\end{tabular}

$E T g^{-/-}: L D L R K O(-/-), E T g^{+/-}: L D L R K O(+/-)$, and $E T g^{+/+}: L D L-$ $R K O$ mice $(+/+)$ were initially maintained on a normal chow, and then on a $1.25 \%$ cholesterol/atherogenic diet and water supplemented with zinc for $14 \mathrm{wk}$. Blood was collected after the feeding. VLDL, IDL, LDL, and HDL were isolated by sequential ultracentrifugation, and their cholesterol contents were determined.

Plasma apo B-100 concentrations were reduced in mice that overexpressed apo E (Fig. 3 and Table III), corroborating the idea that the reduction of non-HDL-C levels is due to a decrease in the particle number of apo B-containing lipoproteins, but not to a decrease in the cholesterol contents in each lipoprotein particle. E+VLDL was enriched with rat apo E compared to E-VLDL (Fig. 1), and cleared faster than E-VLDL when injected into wild-type mice with the functional LDLR (Fig. $4 A$ ), indicating that E+VLDL has higher affinity for the LDLR than E-VLDL. When E-VLDL or $\mathrm{E}+\mathrm{VLDL}$ were injected back into the $L D L R K O$ mice from which the respective VLDL were isolated (Fig. $4 \mathrm{~B}$ ), their plasma clearance rates were four- and sixfold slower than the values for the experiments where wild-type mice were used as recipients. These results indicate that the LDLR has overwhelming contribution to the clearance of these lipoproteins. The difference in the plasma clearance between E-VLDL and E+VLDL was not discernible in the initial $3 \mathrm{~h}$, but $\mathrm{E}+\mathrm{VLDL}$ was cleared faster than E-VLDL after $6 \mathrm{~h}$. As a whole, E+VLDL had higher FCR and lower production rate

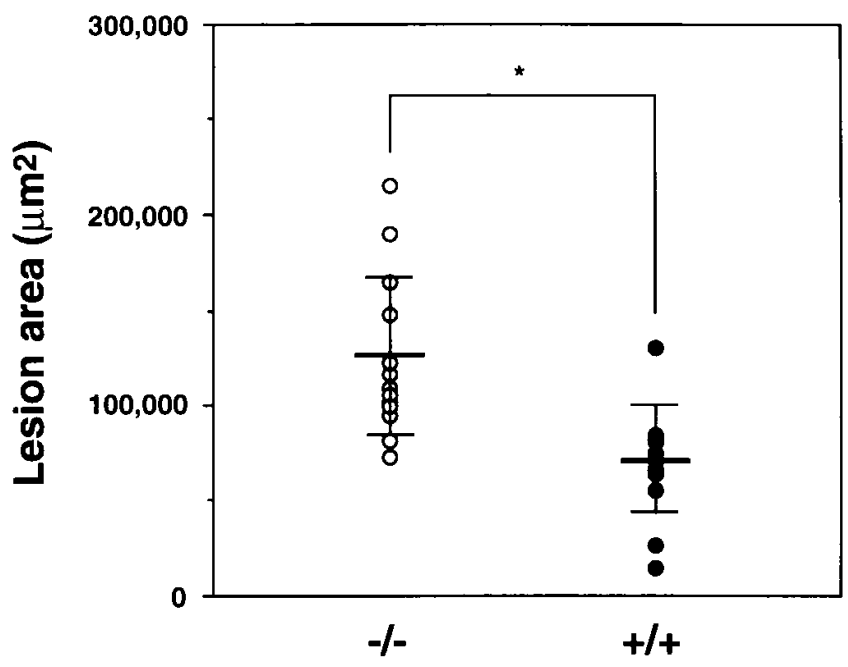

Figure 6. Lipid staining lesion area in the mouse aorta. After feeding a $1.25 \%$ cholesterol/atherogenic diet and water supplemented with zinc for $14 \mathrm{wk}$, the hearts with aortic roots were taken for the evaluation of fatty streak lesion areas. The mean lesion area per section is plotted in each of the $E T g^{-1-}: L D L R K O(O)$ and $E T g^{+/+}: L D L R K O$ mice $(\bullet)$. *denotes the difference at $P<0.001$. 
than E-VLDL, even when injected into mice lacking the LDLR.

Apo E secreted from the liver has been thought to be an important determinant of the clearance of lipoproteins. This secretion-recapture model was initially proposed to explain the local autocrine and paracrine-like function of apo $\mathrm{E}(1,25)$, and was subsequently extended to explain the rapid clearance of CR (26). In agreement with this model, the enhanced clearance of E+VLDL via the non-LDLR pathway may, at least in part, reduce the apo B-100 levels in the $L D L R K O$ mice expressing rat apo $\mathrm{E}$. In addition, VLDL production was reduced in these animals. We speculate that nascent VLDL acquires excess apo $\mathrm{E}$ in the space of Disse, and then is sequestered onto the surface of the hepatocytes followed by endocytosis through a pathway distinct from the LDLR, presumably LRP or heparan sulfate proteoglycans.

In contrast to our previous report showing that the plasma TG levels were markedly reduced in mice expressing apo $\mathrm{E}$ (13), the plasma TG levels in the $E T g^{+/-}: L D L R K O$ and $E T g^{+/+}$: $L D L R K O$ were similar to those in the $E T g^{-1-}: L D L R K O$ mice. This discrepancy can be explained by assuming that the TG-lowering effect of the apo E transgene requires the LDLR, indicating that the apo $\mathrm{E}$ transgene preferentially stimulates the catabolism of TG-rich lipoproteins through the LDLRmediated pathway.

With respect to chylomicron metabolism, the excursion of the plasma retinyl ester after vitamin A load was delayed ninefold in the $L D L R K O$ mice, compared to wild-type mice (13). These observations are consistent with our previous findings that the LDLR plays a pivotal role in the metabolism of chylomicron (27). In the present study, however, no significant difference was observed in the plasma excursion of retinyl ester between the $L D L R K O$ mice with and without the apo E transgene (Fig. 5), which is apparently contradictory to the changes in the VLDL metabolism. This can be explained by the facts that apo E is not overproduced in the intestine (13), and that the intestine lacks such space for enrichment with apo $E$ as the space of Disse.

Diet-induced hypercholesterolemia was suppressed in the $L D L R K O$ mice overexpressing rat apo $\mathrm{E}$ in both a homozygous or heterozygous state (Table IV). In parallel, diet-induced fatty streak lesion formation was suppressed in the $\mathrm{ETg}^{+/+}$: $L D L R K O$ mice (Fig. 6). Because the lesion formation and hypercholesterolemia were suppressed to a similar degree, the cholesterol-lowering effects of the apo E transgene may largely account for the antiatherogenic effects.

Recently, we and other investigators have reported that the introduction of genes such as lipoprotein lipase (11), VLDL receptor $(28,29)$, APOBEC-1 (30), or cholesterol 7 $\alpha$-hydroxylase (31), which are apparently irrelevant to the LDLR, ameliorated hypercholesterolemia in the LDLRKO mice. This kind of strategy may help avoid potential problems such as autoantibody formation against genetically introduced proteins. Pharmaceutical or genetic manipulation of the hepatic apo E production should be a promising adjunctive therapy for homozygous familial hypercholesterolemia.

\section{Acknowledgments}

We would like to thank Kimiko Saito and Mihoko Kusubae for technical assistance.

\section{References}

1. Mahley, R.W. 1988. Apolipoprotein E: cholesterol transport protein with expanding role in cell biology. Science. 240:622-630.

2. Brown, M.S., and J.L. Goldstein. 1986. A receptor pathway for cholesterol homeostasis. Science. 232:34-37.

3. Yamada, N., D.M. Shames, J.B. Stoudmire, and R.J. Havel. 1987. Metabolism of lipoproteins containing apolipoprotein B-100 in blood plasma of rabbits: heterogeneity related to the presence of apolipoprotein E. Proc. Natl. Acad. Sci. USA. 83:3479-3483.

4. Ji, Z.-S., S. Fazio, Y.-L. Lee, and R.W. Mahley. 1994. Secretion-capture role for apolipoprotein $\mathrm{E}$ in remnant lipoprotein metabolism involving cell surface heparan sulfate proteoglycan. J. Biol. Chem. 269:2764-2772.

5. Kita, T., M.S. Brown, D.W. Bilheimer, and J.L. Goldstein. 1982. Delayed clearance of very low density and intermediate density lipoproteins with enhanced conversion to low density lipoprotein in WHHL rabbits. Proc. Natl. Acad. Sci. USA. 79:5693-5697.

6. Ishibashi, S., J. Herz, N. Maeda, J.L. Goldstein, and M.S. Brown. 1994. The two-receptor model of lipoprotein clearance: tests of the hypothesis in "knockout" mice lacking the low density lipoprotein receptor, apolipoprotein E, or both proteins. Proc. Natl. Acad. Sci. USA. 91:4431-4435.

7. Herz, J., U. Hamann, S. Rogne, O. Myklebost, H. Gausepohl, and K.K. Stanley. 1988. Surface location and high affinity for calcium of a $500 \mathrm{kDa}$ liver membrane protein closely related to the LDL-receptor suggest a physiological role as lipoprotein receptor. EMBO (Eur. Mol. Biol. Organ.) J. 7:4119-4127.

8. Willnow, T.E., Z. Sheng, S. Ishibashi, and J. Herz. 1994. Inhibition of hepatic chylomicron remnant uptake by gene transfer of a receptor antagonist. Science. 264:1471-1474.

9. Rohlmann, A., M. Gotthardt, R.E. Hammer, and J. Herz. 1998. Inducible inactivation of hepatic LRP by Cre-mediated recombination confirms role of LRP in clearance of chylomicron remnants. J. Clin. Invest. 101:689-695.

10. Yamada, N., H. Shimano, H. Mokuno, S. Ishibashi, T. Gotohda, K. Kawakami, Y. Watanabe, Y. Akanuma, T. Murase, and F. Takaku. 1989. Increased clearance of plasma cholesterol after injection of apolipoprotein E into Watanabe heritable hyperlipidemic rabbits. Proc. Natl. Acad. Sci. USA. 86:665-669.

11. Mahley, R.W., K.H. Weisgraber, M.M. Hussain, B. Greenman, M. Fisher, T. Vogel, and M. Gorecki. 1989. Intravenous infusion of apolipoprotein $\mathrm{E}$ accelerates clearance of plasma lipoproteins in rabbits. J. Clin. Invest. 83: 2125-2130.

12. Yamada, N., I. Inoue, M. Kawamura, K. Harada, Y. Watanabe, H. Shimano, T. Gotoda, M. Shimada, K. Kohzaki, T. Tsukada. M. Shiomi, Y. Watanabe, and Y. Yazaki. 1992. Apolipoprotein E prevents the progression of atherosclerosis in Watanabe heritable hyperlipidemic rabbits. J. Clin. Invest. 89: 706-711.

13. Shimano, H., N. Yamada, M. Katsuki, M. Shimada,T. Gotoda, K. Harada, T. Murase, F. Fukazawa, F. Takaku, and Y. Yazaki. 1992. Overexpression of apolipoprotein $\mathrm{E}$ in transgenic mice: a marked reduction in plasma lipoproteins except high density lipoprotein, and resistance against diet-induced hypercholesterolemia. Proc. Natl. Acad. Sci. USA. 89:1750-1754.

14. Shimano, H., N. Yamada, M. Katsuki, K. Yamamoto, T. Gotoda, K. Harada, M. Shimada, and Y. Yazaki. 1992. Plasma lipoprotein metabolism in transgenic mice overexpressing apolipoprotein E. Accelerated clearance of lipoproteins containing apolipoprotein B. J. Clin. Invest. 90:2084-2091.

15. Ishibashi, S., M.S. Brown, J.L. Goldstein, R.D. Gerard, R.E. Hammer, and J. Herz. 1993. Hypercholesterolemia in low density lipoprotein receptor knockout mice and its reversal by adenovirus-mediated gene delivery. J. Clin. Invest. 92:883-893.

16. Shimada, M., S. Ishibashi, T. Inaba, H. Yagyu, K. Harada, J. Osuga, K. Ohashi, Y. Yazaki, and N. Yamada. 1996. Suppression of diet-induced atherosclerosis in low density lipoprtein receptor knockout mice overexpressing lipoprotein lipase. Proc. Natl. Acad. Sci. USA. 93:7242-7246.

17. Kotite, L., N. Bergeron, and R.J. Havel. 1995. Quantitation of apolipoprotein B-100, B-48, and E in human triglyceride-rich lipoproteins. J. Lipid Res. 36:890-900

18. Noma, A., T. Yokosuka, and K. Kitamura. 1983. Plasma lipids and apolipoproteins as determinators for presence and severity of angioraphycally defined coronary artery disease. Atherosclerosis. 49:1-7.

19. Kataoka, S., M. Paidi, and B.V. Howard. 1994. Simplified isoelectric focusing/immunoblotting determination of apolipoprotein E phenotype. Clin. Chem. 40:11-13.

20. Havel, R.J., H.A. Eder, and J.H. Bragdon. 1955. The distribution and chemical composition of ultracentrifugally separated lipoproteins in human serum. J. Clin. Invest. 34:1345-1353.

21. Bergeron, N., L. Kotite, and R.J. Havel. 1996. Simultaneous quantitation of apolipoproteins B-100, B-48, and E separated by SDS-PAGE. Methods Enzymol. 262:82-94.

22. Goldstein, J.L., S.K. Basu, and M.S. Brown. 1983. Receptor-mediated endocytosis of LDL in cultured cells. Methods Enzymol. 98:241-260.

23. Matthews, C.M.E. 1957. The theory of tracer experiments with ${ }^{131}$ I-labeled plasma proteins. Phys. Med. Biol. 2:36-53.

24. Paigen, B., A. Morrow, P.A. Holmes, D. Mitchell, and R.A. Williams 1987. Quantitative assessment of atherosclerotic lesions in mice. Atherosclero- 
sis. 68:231-240.

25. Ishibashi, S., N. Yamada, H. Shimano, N. Mori, K. Mokuno, T. Gptoda, M. Mawamaki, T. Murase, and F. Takaku. 1990. Apolipoprotein E and lipoprotein lipase secreted from human monocyte-derived macrophages modulate very low density lipoprotein uptake. J. Biol. Chem. 265:3040-3047.

26. Shimano, H., Y. Namba, J. Ohsuga, M. Kawamura, K. Yamamoto, M. Shimada, T. Gotoda, K. Harada, Y. Yazaki, and N. Yamada. 1994. Secretionrecapture process of apolipoprotein $\mathrm{E}$ in hepatic uptake of chylomicron remnants in transgenic mice. J. Clin. Invest. 93:2215-2223.

27. Ishibashi, S., S. Perrey, Z. Chen, J. Osuga, M. Shimada, K. Ohashi, K. Harada, Y. Yazaki, and N. Yamada. 1996. Role of the low density lipoprotein receptor pathway in the metabolism of chylomicron remnants: a quantitative study in knockout mice lacking the LDL receptor, apolipoprotein E or both. $J$. Biol. Chem. 271:22422-22427.

28. Kobayashi, K., K. Oka, T. Forte, B. Ishida, B. Teng, K. Ishimura-Oka, M. Nakamuta, and L. Chan. 1996. Reversal of hypercholesterolemia in low den- sity lipoprotein receptor knockout mice by adenovirus-mediated gene transfer of the very low density lipoprotein receptor. J. Biol. Chem. 271:6852-6856.

29. Kozarsky, K.F., K. Jooss, M. Donahee, J.F. Strauss, III, and J.M. Wilson. 1996. Effective treatment of familial hypercholesterolemia in the mouse model using adenovirus-mediated transfer of the VLDL receptor gene. Nat. Genet. 13:54-62.

30. Teng, B., B. Ishida, T.M. Forte, S. Blumenthal, L.-Z. Song, A.M. Gotto, Jr., and L. Chan. 1997. Effective lowering of plasma, LDL, and esterified cholesterol in LDL receptor-knockout mice by adenovirous-mediated gene delivery of apo B mRNA editing enzyme (Apobec1). Arterioscler. Thromb. Vasc. Biol. 17:889-897.

31. Spady, D.K., J.A. Cuthbert, M.N. Willard, and R.S. Meidell. 1998. Overexpression of cholesterol $7 \alpha$-hydroxylase (CYP7A) in mice lacking the low density lipoprotein (LDL) receptor gene: LDL transport and plasma LDL concentrations are reduced. J. Biol. Chem. 273:126-132. 